\title{
Urban regeneration through post-war reconstruction: Reclaiming the urban identity of the old city of Mosul
}

\author{
Dr.Shaimaa Hameed Hussein ${ }^{1}$, Zina Riadh Abdulla ${ }^{2}$, Nawras Motathid Mohammed Salih ${ }^{3}$ \\ ${ }^{1}$ Assistant Professor at Al-Nahrain University / College of Engineering / Department of architecture \\ ${ }^{2}$ Assistant Lecturer at Al-Nahrain University / College of Engineering / Department of architecture \\ ${ }^{3}$ Engineer at Al-Nahrain University / College of Engineering / Department of architecture
}

\section{Article Info}

Received Dec. 10, 2018

\section{Keyword:}

Reconstruction

Urban identity

Urban regeneration

Mosul

\begin{abstract}
This paper attempts to shed light on conserving local architectural heritage through the redevelopment and reconstruction of a city suffering from postwar devastation, while maintaining local identity. The city of Mosul is the 2nd largest city in Iraq, with a population of 1.8 million in the year 2014 before the ISIS occupation of the area. This study intents to recommend urban regeneration strategies, to be taken upon during the redevelopment of the old city of Mosul. A set of strategies that may ensure the preservation of the urban identity of the area, while redeveloping and coping with today's environmental, socio-economic and political changes. A thorough theoretical analysis was carried out by the researchers to conclude a set of indicators of urban regeneration strategies to ensure memory, identity and development. The recommendations emphasized on the integration of the new designs with the old urban fabric, also harmonizing the physical environment with the original buildings whether withstanding or destructed. They also referred to the importance of buildings with historical and symbolic values and their role in reclaiming the urban identity and promoting the sense of belonging.
\end{abstract}

\section{Corresponding Author:}

First Author,

Architecture Departement,

Al-Nahrain University,Iraq

Email: shaimaahameed@yahoo.com

\section{Introduction}

Mosul was established on the western bank of the River Tigris in the 6th Century, just across the water from the ruins of the Assyrian city of Nineveh [1]. The city also flourished during the Abbasid era and was considered a major city for trade and governance throughout history. Therefore it was rich with ancient ruins and historical traditional buildings that were still standing across the city up until the IS occupation. The old city of Mosul is a traditional Islamic city and a historic urban center characterized by its dense traditional urban fabric, narrow alleyways and courtyard houses. A massive area of the old city was targeted and bombed throughout the liberation of Mosul due to the various positions taken by IS exploiting the compactness of the urban fabric for defensive reasons.

Each cultural group has its local architectural identity and heritage, related to memory, which gives the city its urban identity [2]. Historic urban centers, like the old city of Mosul, enact in enhancing a place's memory, belonging and identity. The influence of these historic centers spread to include the identity of the bigger city and the surrounding areas [3]. Preserving cultural heritage is inextricably linked to resolving the post-war crisis and ensuring the future of the region and its economic prosperity and stability [4]. 


\section{War and architecture}

Buildings are considered boxes of memories, so, targeting these buildings violently mean targeting people's memories. A cultural group's architecture is deeply connected to their national identity. Hence, an attack on the first targets the national identity too. When this identity is targeted, the feeling of national belonging and the people's collective memory starts to dissipate, and occupants of the area feel displaced and disconnected to their own city. This strategy is used in politics and war as it weakens moral among the people and armies and therefore makes them easier to defeat. So it can be said, that the homeland is directly connected to people's identity. Therefore, the most efficient way to obliterate a community's identity is by destructing and demolishing their homeland

The systemic destruction that occurs in these types of wars does not target randomly. Buildings that reflect historical and symbolic values are selected, so that their destruction would trigger feelings of despair and desperation among their people. Subsequently, the demolition of the cultural heritage of these communities will slowly lead to disintegrating their values, traditions, and finally, their identity.

The places mostly targeted in wars on identity are:

1) Traditional buildings carrying deep values in the historical collective memory throughout the years, generation to generation.

2) Buildings and public spaces with symbolic values drawn in the peoples' conscience e.g. memorials, ancient fortresses, city squares ... etc.

3) Religious and cultural buildings.

4) Buildings known to the people as university and school buildings and the sort.

Usually places which do not carry specific importance to the people's identity are not targeted, as they not serve the cause of these type of wars, and their demolition will not cause the culturally emotional shock desired [5].

\section{Architectural and urban identity}

The architectural identity of a particular local group of people represents a living landscape with a common sense of place that is produced by the community's accumulated efforts over time to contain meanings and way of life that form the national architectural identity [6]. Urban studies researchers have always emphasized on the term "identity". The physical appearance and visual manifestation of a city influence the sense of place, and thereby influence users and the way they navigate and occupy these places according to their design. Identity, however, does not only reflect visual and physical qualities of a place, it is the connection between these qualities and the activities of the occupants' personalities interacting with the place. Urban identity can only be understood throughout time and including the social, cultural, visual and spiritual characteristics and qualities of a building [7].

Local cultural values usually define the type of function contained in a particular architectural space. This connection gives architectural identity its local cultural meaning. In the following statement, UN Habitat emphasized the important role of cultural heritage in cities today; "As a result, planning is being required to preserve and promote cultural heritage, tangible and intangible, of the communities living in cities, since heritage has been recognized to have a role in shaping the city's identity". This statement stresses the significance of cultural heritage regeneration as a means of reclaiming a city's unique and distinguished identity [2].

\subsection{Urban identity}

"The perception of the built fabric has the value and meaning of different objects and physical relationships that people experience in their daily engagement with the city" [8]. Kevin Lynch emphasized that the identity of a place can be perceived and roughly measured by simple tests of recognition, recall and description. Theorists and researchers have struggled to establish an objective definition of urban identity, but a general statement can be claimed of it being the relationship between one's self and the surrounding. Some scholars 
debated that the physical appearance of the built environment indicates a certain identity authenticated by distinctive aspects enfolded in traditional and historical qualities of the urban fabric. These qualities are mainly seen in the space's ability to accommodate and integrate social and cultural interaction. These features will eventually be recognized and memorized by individuals and communities as unique characteristics to the place and its community.

Therefore, identity could be tackled from many angles. In a way, it represents a social and cultural connection between an area and the people living and working there. It also conveys the tangible and intangible aspects of their heritage like buildings, memories and historical incidents.

Urban identity is a combination of the physical heritage of a place, the local culture of its people and its geographical aspects, covered with perceived reminiscences. Furthermore, "City identity is a combination of the aspirations and experiences of the citizens and those who visit". The sense of belonging to a place is manifested through a perception of both the broader urban region and the particular physical places [9].

In conclusion, it can be said that "identity" is deeply connected to time and place. It is also the image and result of the collective decisions of a society. And therefore, it is forever changing with time due to social, cultural, environmental and technological transformations. It is a mirror of society so it must carry continuous and relating characteristics.

\subsection{The need for urban identity}

A city identity is necessary and essential as it delivers harmony between the "constant" and the "changing" elements; people and history, which are incorporated by a shared link that makes a particular city distinguished and unique [10]. The concept of urban identity arises often when discussing matters of heritage. Urban identity is often established by the use of a historic idiosyncratic urban form, architectural style including design characteristics and elements, while employing local and traditional building materials, and structural techniques. "Historic environments with their buildings have provided a unique visual image of the city before they were drawn up in a sea of global environments" [2].

The urban identity is part of the cultural identity of its society. It can only be achieved through the interaction of individuals with their environment. Therefore, it is in permanent reformation due to the materialistic and intellectual abilities of members of society.

\subsection{Urban regeneration vs. saving urban identity}

Cities in post-war circumstances need projects of urban regeneration to achieve urban sustainability after devastation. These projects can only see the light through strategic post-war policies. Inner cities often decline and saving heritage becomes a priority caused by the dangers of lost identity. Declining post-war communities need to work against harsh socioeconomic circumstances such as deactivated areas, the decrease of income as well as the destruction of the city whether it being in the form of bombed buildings or a devastated infrastructure.

The purpose of urban regeneration is regarded as an essential sustainable urban progress. Therefore, three main aspects should be considered. The first is the conservation of historic and cultural centers and the regeneration of urban potential, including the redevelopment of urban central functions and their utilization. The second objective is to ensure residential stability, through the supply of low-income settlements and the improvement of the remaining residential neighborhoods. Policies also strive to achieve stability in the cost and pricing of houses. The third is to improve the environmental quality of the urban environment, including 
pollution and energy consumption levels, by implementing environmentally-friendly and passiveenvironmental-performance strategies [11].

The main objective of urban regeneration is to stimulate economic growth through strategies that change the built environment, while conserving its local identity.

Considering particularly declining ancient city centers, many urban regeneration projects have been launched to revive them due to the permanent shifting in land-use and rapid urban growth in these areas. The same adheres to historic centers and old industrial and harbor sites. The strategies used aim to find solutions to the problems caused by the mentioned factors by improving the physical and economic environment which are the essence of a city's urban identity. In addition to these strategies, and aiming to include inner views and aspirations of the people inhabiting the city, locals are included and their opinions taken at heart while forming the tailored objectives of urban regeneration of a specific area and the means to achieve them. Therefore, the regeneration of historic city centers endeavors to enhance and nurture the local inhabitants' sense of belonging and identity within the history of the place [2].

Change in the urban environment is inevitable due to many factors; war may be one of them. But reclaiming the urban identity is a must, and it can be achieved through its dynamic formation which reflects the interaction of individuals with the civil environment and its transformations.

The identity of a place greatly consolidates the sense of belonging. And sustaining a place's identity can be achieved through forethought urban renewal that accomplishes:

1. Sustaining of the traditional urban fabric of the old city.

2. Reactivating society's hidden potentials.

3. Sustaining the sense of belonging to the city.

4. Reclaiming social and cultural impacts.

5. Sustaining architectural styles, materials and technologies.

6. Enhancing the participation of individuals in decision making regarding their city's destiny.

\section{The city of Mosul before and after the war}

\subsection{The importance of the location}

Mosul is one of Iraq's main cities, alongside the capital, Baghdad, and the city of Basra. Ever since Iraq was part of the great Ottoman Empire, these three cities were the capitals of three Ottoman provinces bearing the same names, Mosul in the north region of Iraq, Baghdad in the middle and Basra to the south. Mosul is a unique and diverse cultural mix due to its many ethnicities of Arabs, Kurds, Yazidis, Shabak and Armenian and Assyrian Christians. Mosul is the main city of the Nineveh Governorate, alongside the culturally rich adjacent towns, villages and suburbs.

Nineveh Governorate comes second regarding population, after the capital, Baghdad. It is the cradle of an ancient civilization spanning thousands of years. People display such religious and sectarian diversity to the point that you will find all spectrum of Iraq represented in the towns and villages of Nineveh. It is known as the "mother of two springs" due to its temperate climate in comparison with the rest of Iraq. It is located on the banks of the Tigris River and has been a vital trading city due to its location throughout history.

\subsection{Mosul after the war}

The city of Mosul suffered dramatically after the war. The old city was severely damaged, and approximately 20,000 buildings were either damaged or destroyed according to initial assessments. A high percentage of these buildings were residential buildings housing the locals of the old city in addition to many historical and 
iconic sites located on the west bank of the river that splits the city in half. The level of destruction is unmatched since the Second World War [12]. See Fig.: (1) and (2).

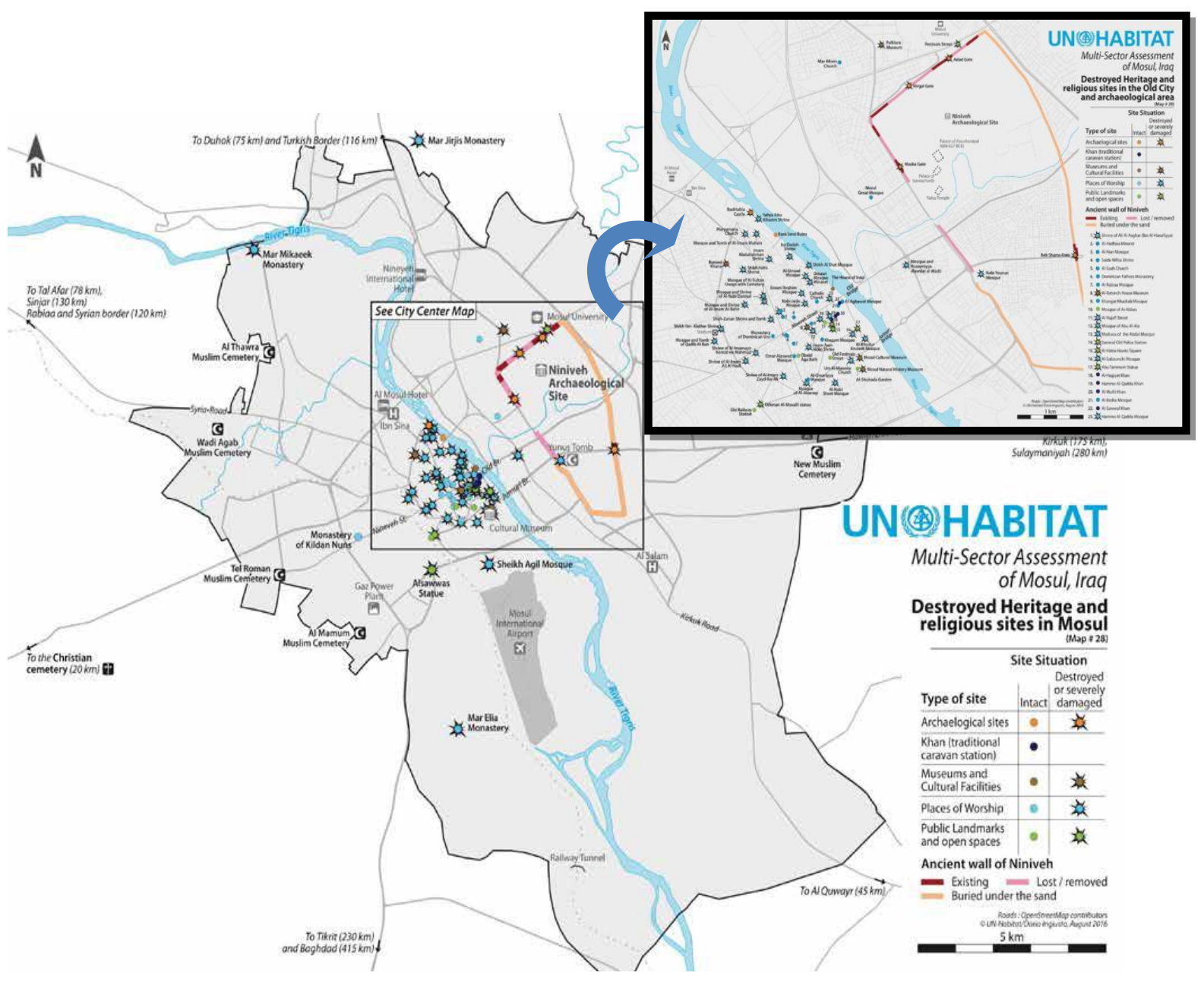

Fig. 1. major centers of destruction according to the UN-habitat post-war assessment [12]

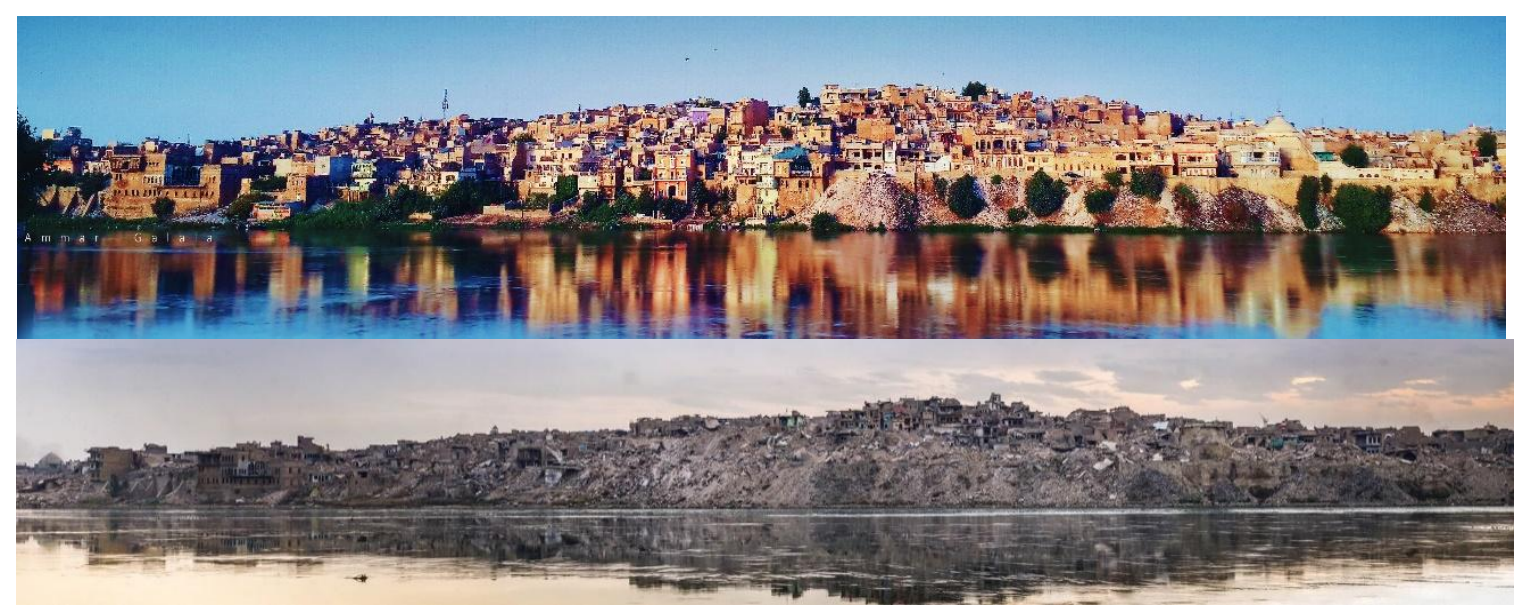

Fig. 2. The panorama of the old city of Mosul before and after the war. Credit of the upper image to Mosul municipality, and lower image taken by Musaab Sami Al-Obeidy. 


\section{Designing the theoretical framework}

The theoretical framework of the research is based on investigating the impact of war and terrorism on place and architecture in the old city of Mosul, with its unique urban characteristics. It also investigates the most appropriate and efficient methods of reconstruction for this war-torn city by adopting the strategy of urban renewal and restoration of the urban layout. See Figure (3).

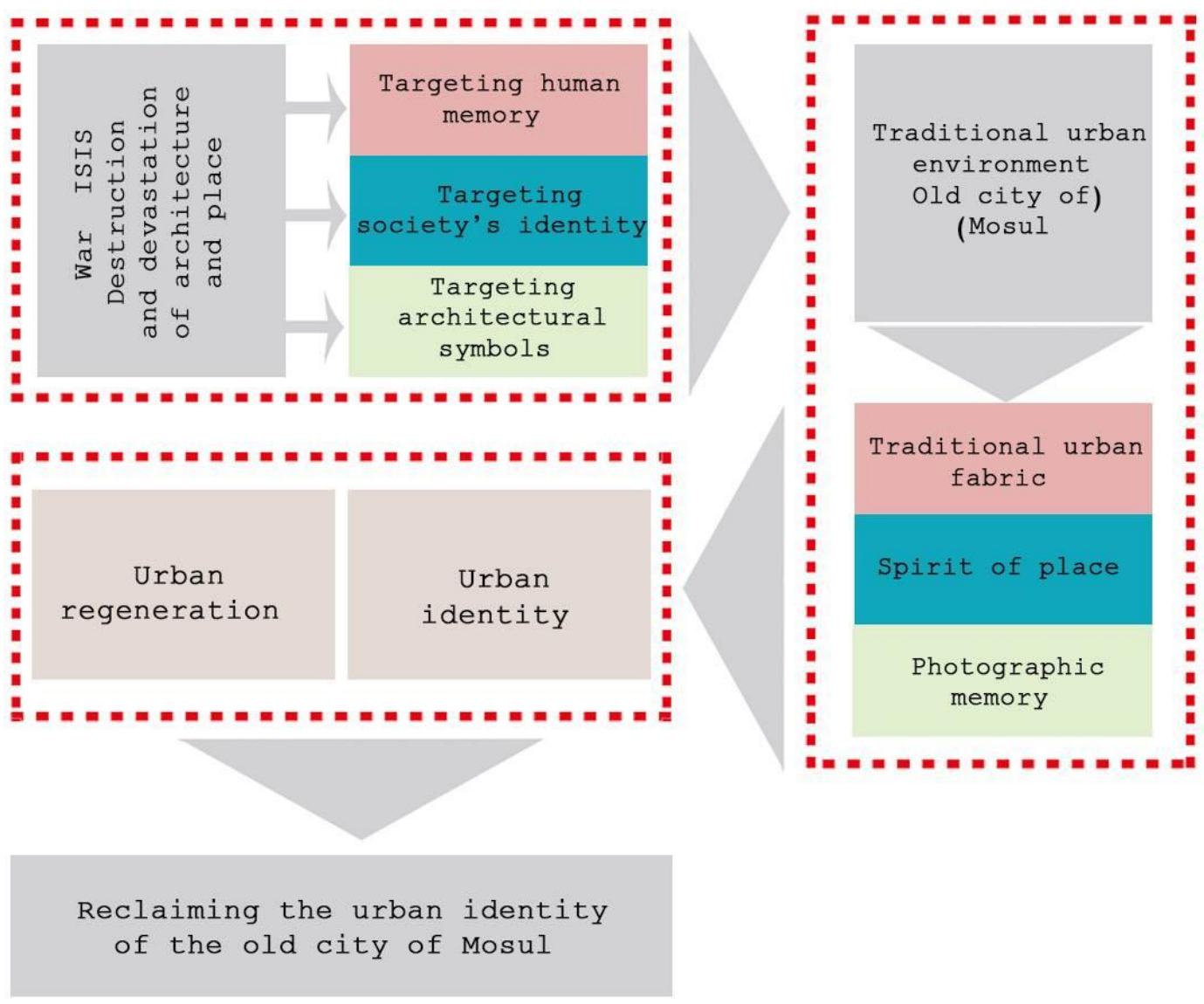

Fig. 3. A diagram illustrating the study's theoretical framework

\section{Conclusion}

The study concluded a list of indicators that support the restoration of the urban identity of the old city. Reclaiming the urban identity of the old city of Mosul through urban regeneration strategies requires:

- Reinforcing and enabling local heritage values.

- Seeing the new through the language of the old by:

- Reclaiming buildings with historical symbolism due to their connection with the people and their sense of belonging. Buildings of such if wiped out, cause a gap in the history of the area and lead to issues of lost identity through following generations.

- Harmonizing values with the original buildings whether them being withstanding, in need of redevelopment or fully destructed.

- Integrating the new urban proposals with the old fabric of the city, while attempting to ensure a physical environment that smoothly promotes economic growth and does not add more challenges to the war-torn area. See Figure 4. 

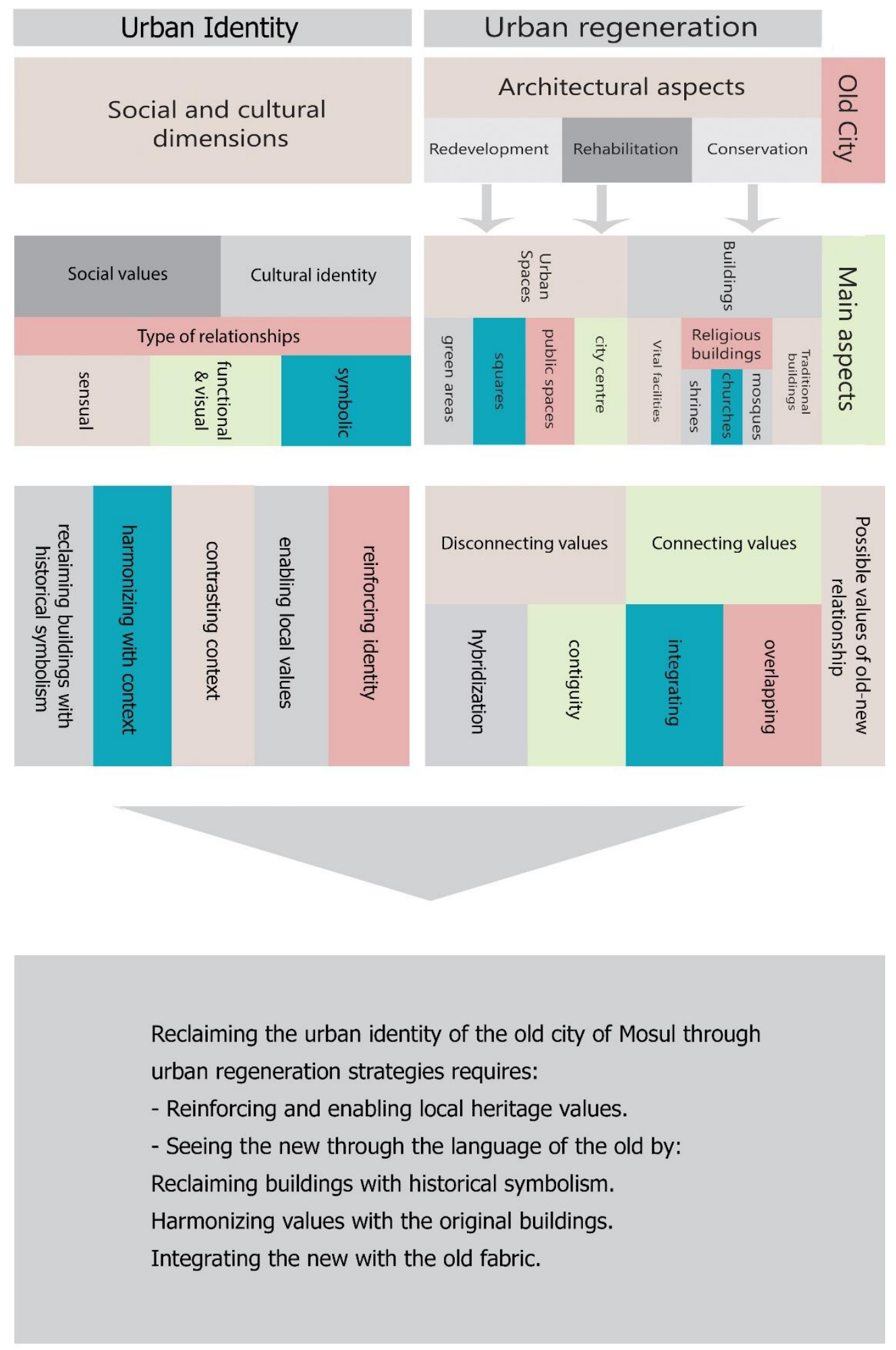

Fig 4. A diagram illustrating the relationship between urban regeneration and urban identity

\section{References}

[1] BBC News, "Mosul: Iraq's beleaguered second city," [online] Available at: https://www.bbc.com/news/world-middle-east-37676731 [Accessed 27 Jan. 2019], 2019.

[2] D. Boussaa, "Urban Regeneration and the Search for Identity in Historic Cities. Sustainability", 10(2), p.48, 2017. 
[3] J. Raadik-Cottrell, "Cultural Memory and Place Identity: Creating Place Experience," Ph.D. thesis, Colorado State University, 2010.

[4] Michael D. Danti, "Ground-Based Observations of Cultural Heritage Incidents in Syria and Iraq," Near Eastern Archaeology, 78(3), p.132, 2015.

[5] Aida Hoteit, "War against Architecture, identity and collective memory International Journal of Development Research," Vol. 5, Issue, 02, pp. 3415-3420, 2015.

[6] M. Najafi and Mustafa Shariff, "The Concept of Place and Sense of Place in Architectural Studies," International Journal of Social, Behavioral, Educational, Economic, Business and Industrial Engineering Vol.: 5, No.: 8, 2011.

[7] Derya Oktay, "How can urban context maintain urban identity and sustainability: Evaluations of Taormina (Sicily) and Kyrenia (North Cyprus)," Web journal: on cultural patrimony, vol. 2, 2006.

[8] K. Lynch, "Good city form," Cambridge: MIT Press, 1989.

[9] Brian Evans, "Urban Identity, Learning from Place II," Routledge, London \& New York, 2011.

[10] K. Lynch, "The Image of the City,” MIT Press: Cambridge, MA, USA, 1960.

[11] K.H. Hwang, "Finding Urban Identity through Culture-led Urban Regeneration", Journal of Urban Management, Vol. 3, No. 1-2, pp. 67-85, 2014.

[12] UN-Habitat, "City Profile of Mosul, Iraq,” October2016. 